\title{
COMUNICAÇÃO SUPLEMENTAR F/OU ALTERNATIVA: FATORES FAVORÁVEIS E DESFAVORÁVEIS AO USO NO CONTEXTO FAMILAR ${ }^{1}$
}

\author{
AugMENTATIVE AND ALTERNATIVE COMMUNICATION: FAVORABLE AND \\ UNFAVORABLE FACTORS LEADING TO ITS USE IN THE FAMILY CONTEXT
}

\author{
Simone KRÜGER ${ }^{2}$ \\ Ana Paula BERBERIAN ${ }^{3}$ \\ Ana Cristina GUARINELLO ${ }^{4}$ \\ Luciana Branco CARNEVALE ${ }^{5}$
}

RESUMO: o objetivo deste estudo foi investigar fatores que contribuem para o uso e o não-uso da Comunicação Suplementar e/ ou Alternativa (CSA) no contexto familiar. Foram sujeitos da pesquisa, 20 pais de crianças inseridas em uma escola especial de Curitiba, destinada a indivíduos com deficiências motoras e múltiplas, divididos no Grupo G1, composto por 9 pais que fazem uso da CSA no contexto familiar e no Grupo G2, por 11 pais que não a utilizam. Os dados foram levantados a partir da realização de entrevistas em torno de questões relacionadas a fatores que interferem no uso e no não uso da prancha de CSA. As condições favoráveis ao uso da CSA no contexto familiar incluem: - o nível de escolaridade e a situação econômica dos pais; a frequência de preparo dos pais quanto ao uso da CSA; o reconhecimento da CSA como recurso linguístico; o entendimento de que tal recurso ajuda no desenvolvimento da oralidade e na satisfação de necessidades básicas; aumentar interações sociais. As condições desfavoráveis consistem em: pais consideram conhecer as necessidades de seus filhos; CSA não satisfaz as suas expectativas; falta de orientação e suporte para uso da CSA; o fato de dificuldades motoras prejudicarem o uso da CSA; ausência de tempo. Os resultados oferecem elementos que podem orientar intervenções fonoaudiológicas com as famílias, nas quais a CSA possa ser concebida como recurso linguístico, proporcionando novas possibilidades discursivas e o estabelecimento das relações dialógicas fundamentais para a constituição das relações sociais e do sujeito.

PALAVRAS-CHAVE: Educação Especial. Comunicação Suplementar e/ou Alternativa. Distúrbios da linguagem. Inclusão. Família.

ABSTRACT: The purpose of the present study was to investigate factors that contribute to the use of AAC in the family context, focusing on communication boards. The survey was undertaken with 20 parents of AAC users at a school for special education in Curitiba, using interviews. Two groups of parents were defined: G1 group uses AAC at home and G2 doesn't. Interviews were formulated in order to identify motives for using or not using AAC in the family context. From the analysis of the interviews, several favorable and unfavorable factors for using AAC in the family context were identified. Favorable conditions for using AAC in the family context included: parents school level and economic situation; frequency of training of parents for use of AAC; recognition of AAC as a linguistic resource; understanding that AAC helps develop oral skills; use of AAC for providing basic needs; use of AAC to broaden interactions in other social circles. Unfavorable conditions for using AAC consisted of the following factors: parents presume to know their child's needs; AAC doesn't apply to parents' expectations; there is a lack of training and support for continuous use of AAC; motor skills hinder AAC use; lack of time to use the communication board. Results offer elements that could be meaningful for speech therapy intervention with families, where AAC could be seen as a linguistic resource, allowing new discursive elements and the establishment of dialogical relationships, which are basic to the constitution of social relations and of the subject.

KEYWORDS: Special Education. Augmentative and Alternative Communication. Language Disorders. Inclusion. Family.

\footnotetext{
${ }^{1}$ Fontes de auxílio à pesquisa: bolsa de mestrado $\mathrm{CNPq}$

${ }^{2}$ Mestre em Distúrbios da Comunicação pela Universidade Tuiuti do Paraná. simonekrueger@hotmail.com

${ }^{3}$ Docente do Programa de Mestrado e Doutorado em Distúrbios da Comunicação da Universidade Tuiuti do Paraná, UTP. asilva@utp.br

${ }^{4}$ Docente do Programa de Mestrado e Doutorado em Distúrbios da Comunicação da Universidade Tuiuti do Paraná, UTP. ana.guarinello@utp.br

${ }^{5}$ Docente do Curso de Graduação em Fonoaudiologia da Unioeste.lucicarnevale@hotmail.com 


\section{INTRODUÇão}

A ComunicaçãoSuplementare/ou Alternativa (CSA) vem se configurando como um campo de estudo/intervenção que, gradualmente, se expande nos âmbitos clínico, educacional e científico, especialmente, entre profissionais da Fonoaudiologia, da Educação Especial e da Fisioterapia/Terapia Ocupacional.

Se estudos apontam a importância da valorização e do uso da CSA nos processos de ensino aprendizagem escolar, o seu uso no contexto familiar, por ser um dos primeiros grupos sociais responsáveis pela apropriação da linguagem, vem ocupando lugar de destaque em abordagens teórico-práticas que enfatizam o papel da família na seleção, na sistematização e no uso de sistemas de Comunicação Suplementar e/ ou Alternativa (LACERDA, 2000; PERES; SANCHES; SERVILHA, 2007; SOUZA, 2006).

Nessa direção, grupos de pesquisadores consideram a CSA como um recurso linguístico que pode mediar relações estabelecidas por sujeitos com graves comprometimentos da oralidade, contribuindo de forma decisiva em seus processos de inclusão social (HUER; PARETTE; SAENZ, 2001; PANHAN, 2001; CHUN, 2003; VASCONCELLOS, 2009). Ressalta-se o papel fundamental que a incorporação de modos de linguagem de natureza corporal e gráfica podem trazer para a construção da autonomia de tais sujeitos (LACERDA, 2000; VON TETZCHNER, 2005; REILY, 2006).

Mediante tais pressupostos entende-se que a linguagem corporal, bem como a linguagem gráfica (símbolos ou imagens) são promotoras e facilitadoras das interações sociais e, portanto, podem ser enfatizadas como formas de CSA, em diferentes contextos, em especial familiar e educacional, por sujeitos que apresentam limitações no uso e no domínio da oralidade (SORO-CAMATS, 2003; BAILEY et al., 2006; REILY, 2006).

A partir de uma perspectiva sociohistórica, parte-se do pressuposto de que por meio das relações sociais os sujeitos constroem as realidades subjetivas e materiais em que estão inseridos (BAKHTIN, 1997; FARACO, 2003). Com base em tal perspectiva, considera-se, ainda, que a linguagens oral, escrita, gráfica, bem como gestual, com equivalente potencial expressivo, mediam as relações sociais e, portanto, ocupam lugar central na constituição dos sujeitos e nos processos de construção e significação das experiências vivenciadas pelos mesmos (LACERDA, 2000; VASCONCELLOS, 2009).

Enfim, a concepção de linguagem como dialógica e constitutiva das relações sociais e dos sujeitos em suas diferentes dimensões, justifica a opção desse estudo pela análise de aspectos referentes à participação do outro/sujeito nos processos de apropriação da linguagem, em especial, que ocorrem no contexto familiar (JONES; ANGELO; KOKOSKA, 1998; PARETTE; BROTHERSON; HUER, 2000; BERBERIAN, 2004; SOUZA, 2006). 
Diante de tais colocações, este artigo tem por objetivo analisar fatores que contribuem para o uso e para o não-uso da CSA no contexto familiar, pelos pais e/ ou responsáveis de crianças que fazem uso da CSA no contexto escolar.

\section{MÉtodo}

Para delimitação dos sujeitos que compõem a pesquisa foi selecionada uma escola pública e filantrópica, localizada na cidade de Curitiba, destinada a crianças e adolescentes com deficiências motoras e múltiplas deficiências, considerada uma das principais instituições educativas na cidade que adotam a CSA. A amostra foi intencional, uma vez que incluiu a pais de crianças usuárias da CSA no contexto escolar. O número de pais participantes do estudo foi definido pela quantidade de crianças usuárias de CSA, na referida escola. A partir dos contatos realizados com a diretora da escola, delimitou-se uma amostra de vinte sujeitos divididos em dois grupos: um composto por nove pais e/ou responsáveis que utilizam a CSA no contexto familiar (G1), outro por 11 pais e/ou responsáveis que não utilizam a CSA nesse contexto (G2). O projeto de pesquisa foi submetido e aprovado pelo Comitê de Ética da Universidade Tuiuti do Paraná, pelo protocolo de número 0050/2007 em 02/07/2007.

Em relação ao instrumento de coleta de dados, foram elaborados quatro roteiros de entrevistas: o primeiro adotado em entrevista com a diretora da instituição escolar; o segundo com os vinte pais e/ou responsáveis; o terceiro com os nove pais e/ ou responsáveis do G1 e o quarto com os 11 pais e/ou responsáveis do G2.

A primeira entrevista, realizada com a diretora da escola, continha sete perguntas fechadas que visavam caracterizar a escola escolhida quanto à quantidade de professores e profissionais de áreas afins inseridos na escola, à quantidade de alunos na escola e à quantidade de alunos que faziam uso da CSA na escola e no contexto familiar.

A segunda entrevista, realizada com os sujeitos do G1 e G2, foi conduzida a partir de oito questões fechadas que versavam sobre a categorização das famílias em relação à situação financeira e profissional, à idade do aluno (filho/a) e dos pais, estado civil dos pais, à naturalidade e ao nível de escolaridade do aluno (filho/a) e dos pais.

A terceira e a quarta entrevistas visavam identificar fatores que interfeririam no uso e no não-uso da prancha de CSA. Para tanto, foram formuladas questões em torno da finalidade do uso da prancha de CSA; dos motivos que os levariam ou não a usar CSA no contexto familiar; do preparo quanto ao uso da CSA; da contribuição da prancha de CSA para o desenvolvimento de seus filhos; dos motivos e das situações de uso da CSA no contexto familiar e das tentativas do uso da CSA ocorridas no contexto familiar. A terceira entrevista, composta por cinco questões, duas fechadas e três abertas, foi aplicada com o grupo G1; a 
quarta, composta por cinco questões, duas fechadas e três abertas, foi dirigida ao grupo G2.

Após serem fornecidas explicações acerca dos objetivos da pesquisa e os sujeitos da pesquisa assinarem o termo de consentimento, foi agendado dia e horário das entrevistas que tiveram duração média de 50 minutos. Conduzida, oral e individualmente, por uma das pesquisadoras e gravadas em fita K-7, as respostas foram transcritas ortograficamente, por um dos pesquisadores e repassadas aos sujeitos da pesquisa para validação. Para tanto, foi solicitado aos entrevistados que lessem o material transcrito, verificando se as informações declaradas durante as entrevistas estavam adequadas. Solicitou-se, caso julgassem necessário, que realizassem modificações e/ou complementações por escrito. Quanto ao local das entrevistas com os pais, 18 ocorreram na sede da escola e duas em suas residências, atendendo à solicitação dos mesmos. A entrevista com a diretora foi realizada na sede da escola.

Quanto à elaboração das questões contempladas na entrevista dirigida aos pais e/ou responsáveis, vale destacar que foi realizado, inicialmente, um testepiloto, com duas mães, que não fizeram parte da amostra desse estudo, uma cujo filho fazia uso da CSA nos contextos familiar e escolar e outra cujo filho fazia uso da CSA apenas na escola. Após esse teste foram realizadas as adaptações necessárias para elaboração da versão final do instrumento.

Todas as respostas fornecidas pela diretora da escola e pelos pais e/ ou responsáveis do G1 e G2 compuseram o corpus de análise desse estudo. Para análise das respostas abertas, foi realizada análise qualitativa, a partir da metodologia denominada discurso do sujeito coletivo (LEFÈVRE; LEFÈVRE, 2005), a qual inclui os seguintes passos: 1) atribuição de um código a cada um dos sujeitos, constituído da letra $F$ e seguida dos números de 1 a 9 para os participantes do G1 e de 10 a 20 para os participantes do G2; 2) leitura inicial minuciosa e exaustiva do conteúdo das respostas dos sujeitos; 3) identificação dos dados relevantes que guardavam pertinência ao objetivo da pesquisa; 4) descoberta dos núcleos comuns de sentido; 5) definição de expressões chaves para categorização e quantificação das respostas e elaboração das tabelas; 6) seleção de respostas para análise qualitativa; 7) interpretação e discussão. Para análise quantitativa dos dados utilizou-se o programa de estatística Sphinx (Versão Léxica) e análises estatísticas, como o teste de Fisher, para analisar a situação econômica dos pais e da situação de escolaridade dos mesmos (unilateral), e o teste de comparação entre duas proporções, para a análise do preparo dos pais acerca da CSA.

\section{Resultados e discussão}

\subsection{Aspectos favoráveis ao uso da CSA NO CONTEXTO familiar}

A análise quantitativa evidenciou um impacto significativo da situação econômica e da escolaridade dos pais no uso da CSA. Pode-se identificar a partir 
do cruzamento realizado entre renda dos entrevistados versus uso e não-uso da CSA uma tendência na utilização da CSA no âmbito familiar conforme o aumento da renda da família. $O$ teste de Fisher aplicado para o agrupamento das faixas de renda mostrou ser significativa a relação entre situação financeira familiar e o uso/ não uso da CSA no contexto familiar (resultado $p=0,0420$ unilateral). Da mesma forma, a partir do cruzamento realizado entre os dados referentes à escolaridade dos pais entrevistados pode-se verificar que, quanto maior o nível escolar, maior a utilização da prancha de CSA, conforme mostraram os resultados do teste de Fischer ( $p=0,0399$ unilateral).

Além desses aspectos, relacionados à situação econômica e escolar da família, a frequência de preparo dos pais para o uso da CSA é referida como um dos aspectos favoráveis ao uso da CSA no contexto familiar. Conforme consta na Tabela 1, 19/20 dos pais entrevistados tiveram pelo menos uma vez informação acerca da CSA, com fonoaudiólogos e/ ou professores, prevalecendo os encontros individuais (78\% no G1 e 55\% no G2). O fator relevante encontrado foi a frequência de encontros realizados entre esses profissionais e os respectivos pais. Pais que tiveram acesso mais de uma vez a instruções acerca da CSA, com maior número no G1, informaram usar a prancha no contexto familiar.

Tabela 1 - Frequência de preparo acerca da CSA

\begin{tabular}{lccc}
\hline Frequência de preparo & G1 & G2 & Total \\
Uma vez & $1(11 \%)$ & $9(82 \%)$ & $10(50 \%)$ \\
Mais de uma vez & $5(56 \%)$ & $1(9 \%)$ & $6(30 \%)$ \\
Não lembra quantas vezes & $3(33 \%)$ & $0(0 \%)$ & $3(15 \%)$ \\
Nenhuma vez & $0(0 \%)$ & $1(9 \%)$ & $1(5 \%)$ \\
Total & $\mathbf{9 ( 1 0 0 \% )}$ & $\mathbf{1 1}(100 \%)$ & $\mathbf{2 0}(100 \%)$ \\
\hline
\end{tabular}

Enfatizando a importância de priorizar o trabalho de formação e preparo com pais, pode-se recorrer a um estudo de Panhan (2001), no qual, após a implementação do denominado Programa de Comunicação Alternativa e Ampliada Familiar (ProCAAF), observou aumento do uso da CSA no contexto familiar. O objetivo desse estudo foi avaliar a utilização desse programa, analisando tanto o desempenho do cuidador, como de crianças portadoras de autismo. Segundo a autora, com a utilização desse programa, foi possível avaliar a situação de interação entre as crianças autistas avaliadas e seus cuidadores no ambiente familiar e capacitar os familiares em relação ao uso da CSA (PANHAN, 2001).

Pode-se verificar, ainda, conforme a Tabela 2 e a Tabela 3, que o reconhecimento da CSA como recurso linguístico, também, exerceu impacto positivo no seu uso no contexto familiar. Tal posição pode ser constada nas respostas fornecidas, pelo G1 e G2, acerca da função do uso da CSA na escola e, nas fornecidas pelo G1, a respeito dos motivos que os levam a utilizar a CSA no contexto familiar, apresentadas, respectivamente, na Tabela 2, sob a categorização 
"para conversar, dizer" e "para se expressarem e compreendê-los" e, na tabela 3, sob as categorias "para que o seu filho se coloque melhor", "para compreender melhor o filho" e " para conversar, dialogar".

Tabela 2 - Finalidade do uso da CSA na escola

\begin{tabular}{lcc}
\hline Finalidade do Uso & G1 & G2 \\
$\begin{array}{l}\text { Atendimento das necessidades básicas e das atividades } \\
\text { da vida diária }\end{array}$ & $2(22 \%)$ & $2(18 \%)$ \\
Para se comunicar com outras pessoas & $0(0 \%)$ & $3(27 \%)$ \\
Para expressarem e compreendê-los & $5(56 \%)$ & $2(18 \%)$ \\
Para a aprendizagem & $0(0 \%)$ & $1(9 \%)$ \\
Para conversar, dizer & $2(22 \%)$ & $3(27 \%)$ \\
Total & $\mathbf{9 ( 1 0 0 \% )}$ & $\mathbf{1 1}(100 \%)$ \\
\hline
\end{tabular}

Tabela 3 - Motivos do uso da CSA no contexto familiar (G1)

\begin{tabular}{lc}
\hline Motivos do Uso da CSA (G1) & Frequência absoluta \\
\hline Para que o filho se coloque melhor & 4 \\
Compreender melhor o filho & 4 \\
Para conversar, dialogar & 3 \\
Facilitar a compreensão de seu filho por outras pessoas & 1 \\
Para promover a oralidade & 1 \\
Total de citações & $\mathbf{1 3}$ \\
\hline
\end{tabular}

A importância da utilização da CSA como recurso linguístico que favorece as relações entre pais e filhos pode, também, ser verificada nas respostas a seguir apresentadas: "Para falar através da prancha"(F5); "Para conversar e quanto às atividades de banheiro, pedir comida... não porque ele pede" (F9).

Evidencia-se a partir dessas respostas que os pais reconhecem seus filhos como interlocutores que possuem um "querer dizer", um intuito discursivo e que podem estabelecer relações de sentido a partir dos recursos da CSA. Constatase, ainda, que os pais identificam outras maneiras, para além da oralidade, de terem acesso aos dizeres de seus filhos. Nessa direção, segue, ainda, fragmentos da resposta de F7: “...por causa da prancha, ele aprendeu a fazer sinal com a mão". Pode-se observar, nessa resposta, o reconhecimento de que interações mediadas pela CSA contribuem para o desenvolvimento e uso da linguagem corporal, fundamental em se tratando de crianças com dificuldades de oralidade. 
Ressalta-se, também, que a prancha de CSA é concebida como um recurso que amplia as possibilidades das crianças narrarem experiências vividas fora de seu contexto familiar: "Eu uso na conversa do dia a dia, por exemplo, o que aconteceu na escola" (F5); "Quer falar do amiguinho da escola, ele vai lá e ele mostra o ônibus e a gente já sabe o que" (F7).

Como fator favorável ao uso da CSA, os pais referiram a dificuldade de interpretar e atribuir sentido às manifestações de linguagem. Tal posição pode ser apreendida nos dados apresentados na Tabela 2, os quais evidenciam que 5/9 dos pais afirmaram que usam a CSA para a expressão e compreensão, bem como na colocação de F3: "Quando ela não usava a prancha, a gente ficava em casa tentando se comunicar, ela mostrava o jeito dela, mas tanto ela como nós não entendíamos". Dificuldades de interpretação de movimentos corporais, gestos, expressões faciais e vocalizações produzidas pelo seu filho motivam a utilização da prancha visando significar as suas manifestações. Assim como os sujeitos da pesquisa mencionaram limitações para atribuir sentidos às manifestações e ações dos filhos como fator motivador do uso da CSA, pode-se verificar resultados de estudos que revelam que os pais que usam gestos e língua de sinais afirmam a necessidade de encontrar outros recursos que forneçam a compreensão de seus filhos (CHUN, 2003; VASCONCELLOS, 2009).

O entendimento de que a CSA favorece o desenvolvimento da oralidade, pode ser verificado nos dados apresentados na Tabela 3 sob a caracterização "para promover a oralidade", bem como, na resposta de F7: "... a gente não quer que ele viva só através do gesto... a gente sabe que ele tem condições de falar, então a gente usa a prancha para tentar ajudar ele a saber o que ele quer e tentar falar aquilo que ele quer. Falar... pelo menos os sons para a gente entender o que é, e com a figura ajuda".

Referências de que o uso da CSA justifica-se para o atendimento das necessidades básicas e atividades de vida diária, podem ser apreendidas nos dados apresentados na Tabela 2, uma vez que 2/9 pais remetem a finalidade do uso da CSA a tal função, como, também verificadas nas respostas de F1 e F3: “... para saber ir ao banheiro quando esta com fome e com sede" (F1); "Quando pede para ir ao banheiro, quando quer água e alguma coisa" (F3). Tais dados evidenciam que as situações interativas, estabelecidas entre pais e filhos, visam atender à satisfação das necessidades básicas da criança, bem como ao cumprimento de uma rotina.

O uso da CSA para facilitar as interações fora do contexto familiar foi apontado como aspecto favorável ao uso nesse último contexto, conforme dados apresentados na Tabela 3, bem como, as respostas de F1: “...você usa mesmo para ela poder se comunicar com quem ela não conhece" e de F2: "Para a professora se comunicar com o meu filho, quando ela não consegue entendê-lo". Pode-se apreender que pais usam a CSA no contexto familiar para que outras pessoas, fora desse contexto passem a fazer uso de tal recurso e possam compreender melhor seus filhos. Enfatizando a importância da CSA para mediar relações fora do núcleo familiar, os pais identificam a CSA como um meio facilitador da inclusão social do filho, especialmente, no universo escolar. Tal posição aparece em resultados encontrados 
por Angelo, Kokoska, Jones (1996), pois ao pesquisarem as expectativas dos membros familiares acerca do uso da CSA, verificaram a afirmação dos pais de que tal uso favorece a integração social de seus filhos. Semelhante conclusão foi apresentada em estudo, com base em relatos de pais que afirmavam que o uso da CSA ampliou e facilitou as oportunidades sociais de seus filhos, principalmente com usuários mais velhos (BAILEY et al., 2006).

\subsection{Aspectos desfavoráveis aO USO da CSA NO CONTEXTO FAMILIAR}

Feitas as análises em torno dos aspectos favoráveis ao uso da CSA, serão apresentados e discutidos, a seguir, os aspectos desfavoráveis ao uso da mesma no contexto familiar referidos pelos sujeitos dessa pesquisa. Dentre tais aspectos, além da baixa renda familiar e o baixo nível de escolaridade, já mencionados, os pais referiram: o fato de entender seus filhos; falta de tempo; limitações físicas dos filhos, o fato da CSA não ser funcional.

A afirmação de que os pais não usam a CSA no contexto familiar por entenderem seus filhos foi recorrente conforme apontam os dados das Tabelas 4 e 5 e as respostas de F12: "o que ela comunica com a gente a gente já sabe...". "Ela não fala, mas pelo gesto dela, entendemos tudo o que ela comunica". Outros estudos apresentam posições de pais que referem entender seus filhos independentemente da forma como se colocam (PANHAN, 2001; PARETTE; BROTHERSON; HUER, 2000; PAULA; NUNES, 2004).

Tabela 4 - Motivos do não-uso da CSA (G2)

\begin{tabular}{lc}
\hline Motivos do Não-Uso da CSA (G2) & Frequência absoluta \\
\hline Entender o filho & 5 \\
Falta de tempo & 4 \\
Falta de condições físicas do usuário & 1 \\
A CSA não ser funcional & 2 \\
Falta de treino/ habilidade & 1 \\
Recusa por parte do usuário & 1 \\
Total de citações & $\mathbf{1 4}$ \\
\hline
\end{tabular}


Tabela 5 - Referências a tentativas de uso da CSA (G2)

\begin{tabular}{lc}
\hline Tentativas de uso da CSA & Frequência absoluta \\
\hline Não deu continuidade por falta de tempo & 1 \\
Não tentaram & 1 \\
Fazem tentativas nas férias & 2 \\
Fazem tentativas algumas vezes & 2 \\
Não deu continuidade porque a prancha não funciona & 1 \\
Não deu continuidade porque o filho não quer usar em casa & 1 \\
Não deu continuidade por dificuldade motora & 1 \\
Tentou, mas desistiu, por entender seu filho & 2 \\
Total de citações & $\mathbf{1 1}$ \\
\hline
\end{tabular}

A afirmação dos pais de que entendem tudo o que seus filhos "falam", sugere que os mesmos acabam por ocupar, simultaneamente, o papel do locutor e do interlocutor, desconsiderando que as relações se estabelecem a partir de interações e situações de diálogos, que envolvem pelo menos duas pessoas diferentes que não tem acesso direto e absoluto do que se passa e do que é manifestado com e pelo outro. Mediante um contexto de relação em que os pais, apesar das limitações de linguagem apresentadas por seus filhos, pressupõem entendê-los de forma plena, pode-se supor que os efeitos e os sentidos construídos pelos pais, acerca de seus filhos e de suas necessidades, sejam constituídos independentemente da qualidade e efetividade das manifestações de linguagem produzidas por seus filhos. Se é necessário que os pais assumam um papel ativo na interpretação das manifestações de seus filhos, é fundamental que os mesmos não sejam colocados numa posição de passiva, não favorável ao desenvolvimento da linguagem em suas diferentes modalidades: oral, escrita e corporal. O reconhecimento da alteridade como condição para o estabelecimento de relações em que ambos interlocutores sejam reconhecidos como sujeitos da linguagem; a concepção de linguagem enquanto fenômeno simbólico e sujeito a interpretações subjetivas (BAKHTIN, 1997; BERBERIAN, 2004; FARACO, 2003), nos permite questionar as afirmações dos pais de que conhecem plenamente seus filhos, suas necessidades e suas manifestações. Ou seja, ressalta-se o fato de que além dessa suposição restringir o uso da CSA como recurso facilitador das interações sociais, limita as possibilidades dos sujeitos avançarem no desenvolvimento de sua linguagem.

O reconhecimento dos filhos como interlocutores passivos, devido às suas limitações orgânicas foi, também, constatado em estudo realizado por Vasconcellos (2009), no qual as dificuldades motoras de sujeitos com paralisia cerebral tendiam a limitar a visão sobre esse sujeito como um organismo deficiente, mascarando deste modo possibilidades de se colocarem como interlocutores ativos. Abordagens fonoaudiológicas que priorizam o uso da CSA, além de objetivar a ampliação das possibilidades de constituição do sujeito em suas diferentes Rev. Bras. Ed. Esp., Marília, v.17, n.2, p.209-224, Mai.-Ago., 2011 
dimensões, devem ressignificar o impacto das limitações orgânicas, oferecendo aos pais a possibilidade de compreenderem que, além da oralidade, existem diferentes formas de manifestação da linguagem que podem ser desenvolvidas e aperfeiçoadas por seus filhos (PAULA; NUNES, 2004; PANHAN, 2001). Apesar das limitações orgânicas, devem ser criadas condições para que os pensamentos, os sentimentos, as necessidades dos sujeitos se materializem em modos de linguagem que, continuamente, avancem em seu valor expressivo e complexidade e, assim, possam ser apreendidas e interpretadas pelos seus interlocutores em sua alteridade. Tais possibilidades são apontadas por Givigi (2007), a partir de um trabalho com grupo composto por seis famílias e acadêmicos de Fonoaudiologia, cujo objetivo era discutir temas trazidos pelos próprios pais, relacionados a dificuldades enfrentadas no estabelecimento de diálogo e de relação com seus filhos. Segundo a autora, após 24 encontros, os pais passaram a observar mais atentamente as manifestações de seus filhos e começaram a descobrir formas de interagir que favoreceram as relações entre pais e filhos.

Posições reveladas pelos pais acerca do fato de não fazerem uso da CSA por entenderem seus filhos permitem também verificar que a linguagem pode ser vivenciada, prioritariamente, para atender a uma função comunicativa. A partir de tal perspectiva, expressões, gestos, vocalizações tendem a serem compreendidos enquanto mensagens simplificadas que cumprem funções, em geral, relacionadas às necessidades e atividades rotina diária.

De qualquer forma, há de se considerar que a referência em relação à facilidade de entendimento dos pais em relação a seus filhos, pode estar assentada na natureza peculiar que, de forma geral, caracteriza o vínculo entre pais e filhos. Tais relações são permeadas por intimidade e por um compartilhar significativo de experiências. "Ela não fala, mas pelo gesto dela, entendemos tudo o que ela comunica" (F12). Pode-se analisar que os pais também se apóiam em modos pessoais (sistemas idiossincráticos), gestos, expressões faciais e manifestações corporais singulares, usados pelos seus filhos para estabelecimento das relações familiares. Quanto a este fato, pode-se recorrer a Deliberato e Alves (2007), ao referirem que um dos fatores do não-uso da CSA pode estar associado ao forte vínculo estabelecido com a mãe, a partir das manifestações não-verbais. Outro estudo, também, constatou que as mães são capazes de "ler" nos olhos de seus filhos o que eles querem num determinado contexto, contudo referem falhar no entendimento do que desejam, quando há envolvimento de sentimentos mais profundos (FERNANDES, 1999). Nota-se, em tal estudo, que movimentos corporais da criança, ainda que rudimentares, foram compreendidos e atendidos enquanto solicitações relacionadas às necessidades básicas e da rotina diária

Outra perspectiva de análise, quanto ao fato dos pais alegarem compreender bem seus filhos sem fazer uso da CSA, refere-se à posição ativa e responsiva pelos mesmos, a partir da qual estão autorizados a interpretar entonações/vocalizações/ movimentos corporais produzidos pelos seus filhos. Tal posição pode ser ainda mais intensificada nas interações entre pais e filhos com limitações orais, conforme 
o relato: "... se ele dá o gemido dele lá, a gente sabe que é xixi, só pela entonação a gente vai como papagaio. Se é o número dois, a gente já sabe, se ele quer tomar banho, se ele quer escutar jogo no rádio, já sabe" (F19). Se o intuito discursivo é reconhecido pelos pais, as manifestações de seus filhos são concebidas como linguagem, se há linguagem, há condição para uma atitude responsiva ativa, geradora de respostas e, portanto, da alternância de posições discursivas entre os sujeitos "falantes", condição para o estabelecimento do jogo dialógico. Tal entendimento permite analisar como tais pais recebem o "som da voz", um "gemido" e as diferentes entonações como enunciados produzidos e passíveis de interpretação, dado o contexto em que se inserem (BAKHTIN, 1997; BERBERIAN, 2004; FARACO, 2003).

Feitas as análises acerca do impacto nos pais da idéia de que compreendem bem seus filhos sem necessitarem da prancha de CSA, é importante considerar que não se trata de desqualificar e/ou duvidar das possibilidades de interpretação/ entendimento dos pais acerca de seus filhos, quer seja pela intimidade/proximidade do vínculo que geralmente caracteriza a relação pais-filhos, quer seja pela posição de interpretantes, usualmente assumida pelos mesmos, por reconhecer seus filhos como sujeitos "falantes". A reflexão que se propõe se refere ao reconhecimento da impossibilidade de apreensão objetiva e absoluta do sujeito, seja ele quem for pela linguagem, isso porque sujeito e linguagem são entidades simbólicas e, nessa medida, não existem limites e interpretações conclusivas e estanques. O outro e a linguagem são sempre passíveis de novas interpretações e as suas relações marcadas pela alteridade (BAKHTIN, 1997; BERBERIAN, 2004; FARACO, 2003).

Além do aspecto acima analisado, alguns pais afirmam que o uso da CSA não atende às suas expectativas, devido à prancha de CSA não ser funcional, conforme indicado na Tabela 4 e na colocação de F16:
A prancha vai todos os dias, só que a dela não é completa. Ela fala o que gosta entende? Tendo alguma coisa que, por acaso, eu não entendi, se tiver na prancha, pra mim é melhor. Eu esqueci de perguntar para a professora se eu posso mandar as coisas que eu entendo, porque eu não sei desenhar.

Verifica-se nessa resposta que a confecção da prancha é responsabilidade da professora, fato que pode resultar na percepção da prancha como pouco funcional no contexto familiar.

Contudo, considerando que a escolha dos símbolos deve ser realizada em função dos contextos reais de interação, ou seja, definidos a partir das condições de produção dos discursos e, portanto, determinados em função de quem fala, para quem fala, com que finalidade, em que momento, em que lugar, vale indagar se o fato do sujeito circunscrever a construção da prancha ao contexto escolar e apenas sob a responsabilidade da professora, está articulado a falta de tempo mencionada como um fator limitante, conforme aponta a Tabela 4 . De qualquer forma, podese notar que os símbolos incluídos na prancha, mencionados por F16, não são efetivos, pois não são pertinentes às especificidades e demandas das interações estabelecidas entre ele e sua filha. 
Oferecendo elementos que permitem avançar na análise dos aspectos acima mencionados, cabe ressaltar achados de um estudo realizado por Parette, Brotherson, Huer (2000), cujo objetivo foi verificar o que famílias de diferentes etnias esperavam dos profissionais quanto às decisões do uso da CSA. Tais achados revelaram que os pais reivindicaram maior participação nos processos de avaliação e seleção dos recursos da CSA e relataram que, além de suas posições não serem consideradas, as escolhas dos símbolos foram baseadas em contatos curtos com a criança, sendo considerado de forma insuficiente o estilo de vida da família.

Considerando tal estudo, chama atenção o fato da falta e ou da restrição de auxílio e preparo para o uso da CSA, serem indicadas, dentre os dados apresentados na Tabela 4 e Tabela 2, como um fator desfavorável ao uso da CSA, bem como, apontadas na fala de F10, que espera que lhe ensinem como usar a prancha: "... também falta habilidade da gente. Um treinamento básico, reforço com as mães de fazer, de entender alguma função da prancha, porque para a gente só colocar a prancha na mão, não sabe nem como lidar. De repente mostrar alguma atividade". Tal resposta além de apontar para a expectativa de F10 aprender a utilizar os recursos da CSA, evidencia a necessidade do implemento de intervenções que abordem a natureza e a utilização de tal recurso. Identificando tal necessidade, alguns estudos, demonstram que existe uma expectativa por parte dos pais de que esse processo de ensino-aprendizagem seja conduzido por profissionais especializados (ANGELO; KOKOSKA; JONES, 1996; LACERDA, 2000; PAULA; NUNES, 2004).

Embora os dados encontrados nesse estudo, a exemplo de outros, sinalizem para a expectativa dos pais em aprender a usar a CSA, cabe ressaltar que intervenções pautadas em treinamentos pontuais tendem a não contribuir de forma significativa para o entendimento e uso da CSA. O desenvolvimento de intervenções que promovam, de forma sistemática e contínua, discussões e práticas, em torno da diversidade de possibilidades de uso e de recursos destinados ao desenvolvimento da CSA e que sejam orientadas no sentido de explicitar a complexidade, a subjetividade e a particularidade que caracterizam a linguagem, assim como as relações por ela mediadas tendem a apresentar resultados mais efetivos (LACERDA, 2000; PAULA; NUNES, 2004).

Como outro fator desfavorável ao uso da CSA, pode-se apreender, ainda, nas respostas dos pais do G2, limitações físicas de seus filhos, conforme dados apresentados nas Tabelas 4 e 5, e em afirmações de F19:

Não tem como! Como é que eu vou fixar a prancha? Ele derruba e, se ele se curva, ele perde o movimento da mão. Ele está indo no desenho, ele levanta a cabeça, dai a prancha sai do lugar. Ele aponta, dai perde... ele diz que não é o que queria apontar.

Ressalta-se a existência de recursos de alta tecnologia que poderiam, em muitos casos, diminuir os impactos das dificuldades motoras que comprometem o uso da prancha. No entanto, dois aspectos devem ser destacados para que não se incorra no erro de considerar tais recursos suficientes para superar as limitações dos sujeitos em questão: 1) a forma como tais recursos são utilizados mediando as relações, contribuindo ou não para tal superação; 2) o acesso restrito que grande 
parte da população brasileira tem em relação aos recursos de alta tecnologia, tendo em vista o custo financeiro dos mesmos.

Nota-se, ainda, conforme dados apresentados nas Tabelas 4 e 5, e afirmação de F10 a falta de tempo de alguns pais para usar a CSA no contexto familiar: "É o tempo! Tempo de ficar sentada conversando com ele" (...) "...eu vou ser honesta, não tive tempo mesmo". É importante ressaltar que, em geral, crianças com limitações motoras requerem vários cuidados extras, além de dependerem de seus pais para suprir necessidades básicas. Muitos pais alegam que, depois de realizarem esses cuidados básicos, pouco tempo resta para "conversarem" com seus filhos. É reconhecido que a "fala no apontar", as formas de indicação dos símbolos, independentemente da estratégia utilizada, seja ela de baixa ou alta tecnologia, é mais lenta do que o diálogo "face a face". Como citado por SoroCamats (2003), muitas vezes é difícil para os interlocutores mudarem as formas de interação, conversação com o locutor. Dialogar com a prancha requer ainda mais tempo, pois se deve esperar o apontar, muitas vezes um apontar impreciso e limitado pela dificuldade motora ou o apontar pelo olhar, utilizando a forma de varredura, solicitando ainda mais tempo.

\section{CONSIDERAÇões FINAIS}

A partir desse estudo pode-se apreender, dentre os aspectos favoráveis ao uso da CSA no contexto familiar: o nível de escolaridade e a situação econômica dos pais, a frequência de preparo dos pais para o uso da CSA; o reconhecimento dos pais da CSA como recurso linguístico; da dificuldade de interpretar e atribuir sentido às manifestações de linguagem; de que a CSA favorece o desenvolvimento da oralidade; da CSA como recurso para atender necessidades básicas; da CSA como recurso facilitador das interações fora do contexto familiar.

Dentre os aspectos desfavoráveis ao uso, pode-se identificar: o fato dos pais afirmarem compreender seus filhos sem necessidade do uso da CSA; o fato dos pais considerarem que a CSA não atender às suas expectativas; a falta de auxílio e preparo para o uso da CSA; as dificuldades e limitações motoras de seus filhos; a falta de tempo.

Os fatores favoráveis e desfavoráveis ao uso da CSA no contexto familiar, evidenciados nessa pesquisa, oferecem elementos que podem orientar intervenções com famílias de sujeitos portadores de graves dificuldades de oralidade. Quanto ao preparo dos pais acerca dos recursos da CSA, foi constatado neste estudo que a frequência do mesmo aparece como fator importante para o uso da CSA pelos pais no contexto familiar.

Tal fato aponta para a necessidade de uma atuação sistemática junto à família, conduzida por equipe interdisciplinar, que viabilize relações de troca entre profissionais e os pais de modo: a permitir que os pais apresentem suas dúvidas e expectativas acerca de aspectos envolvidos com o uso da CSA; a oferecer aos 
pais elementos que permitam participar de forma ativa da construção e uso da prancha de CSA; oferecer elementos aos pais que permitam compreender recursos extralinguísticos como linguagem e, portanto, a ação mediadora da CSA como facilitadora do processo de desenvolvimento da linguagem.

Enfim, tal estudo aponta a necessidade de que intervenções junto aos pais promovam um espaço de escuta que possa acolher as necessidades dos pais, bem como, de discussões de temas como a valorização e o reconhecimento do potencial linguístico de outras modalidades de linguagem além da oralidade, como as manifestações gestuais e sonoras de seus filhos. Dessa forma, tais intervenções poderão contribuir para que a CSA seja concebida como recurso que pode proporcionar novos elementos discursivos, possibilitando o implemento das relações dialógicas, fundamentais para a constituição de sujeitos com maior autonomia e participação social.

\section{REFERÊNCIAS}

ANGELO, D.; KOKOSKA, S.; JONAS, S. A family perspective on augmentative and communication. Families of adolescents and Young adults. Augmentative and Alternative Communication, v.12, p.13-20, 1996.

BAKHTIN, M. Marxismo e filosofia da linguagem. 8. ed. São Paulo: Hucitec, 1997.

BAILEY, R. L. et al. Family members perceptions of augmentative and alternative communication device use. Language Speech and Hearing Services in Schools, v. 37, p. 50-60, 2006.

BERBERIAN, A.P. Psicogênese da linguagem oral e escrita. Curitiba: IESDE. 2004.

CHUN, R.Y.S. Comunicação suplementar e/ou alternativa: favorecimento da linguagem de um sujeito não falante. Pró-Fono Revista de Atualização Científica, Barueri, v.15, n.1, p.5564, 2003.

DELIBERATO, D.; ALVES, A.V. Habilidades expressivas de um aluno não falante com diferentes interlocutores. In: NUNES, P. O. R. L.; PELOSI, B. M.; GOMES, R. M. (Org.). Um retrato da comunicação alternativa no Brasil. Relatos de Pesquisas e Experiências, v. 1. Rio de Janeiro: Quatro Pontos, 2007, p. 137-142.

FARACO, C.A. A Linguagem e diálogo: as idéias lingüísticas do círculo de Bakhtin. Curitiba: Criar, 2003.

FERNANDES, A. S. Protocolo de avaliação para indicação de sistemas suplementares ou alternativos de comunicação para crianças portadoras de Paralisia Cerebral. 1999. $147 \mathrm{f}$. Dissertação (Mestrado em Distúrbios da Comunicação Humana) - Escola Paulista de Medicina, Universidade Federal de São Paulo, 1999. 
GIVIGI, N. C. R. A mediação fonoaudiológica na interlocução entre pais e filhos com dificuldade de linguagem e comunicação. In: NUNES, P. O. R. L.; PELOSI, B. M.; GOMES, R. M. (Org.). Um retrato da comunicação alternativa no Brasil. Relatos de Pesquisas e Experiências, v. 1. Rio de Janeiro: Quatro Pontos, 2007.

HUER, M.; PARETTE, H. P. L.; SAENZ, T. I. Conversations with mexican americans regarding children with disabilities and augmentative and alternative communications. Communications Disorders Quaterly, v.22, p.197-206, 2001.

JONES, S.; ANGELO D.; KOKOSKA, S. Stressors and family supports: Families with children using augmentative and alternative communication technology. Journal of Children Communication Development, v.20, p.37-44, 1998.

LACERDA, S. M. Interação entre familiares e usuários de comunicação alternativa: padrões de comunicação e efeitos de um programa de treinamento. 2000. 205f. Dissertação (Mestrado em Psicologia) - Universidade do Estado do Rio de Janeiro, Rio de Janeiro, 2000.

LEFÈVRE, F.; LEFÈVRE, C. M. A. Discurso do sujeito coletivo: um novo enfoque em pesquisa qualitativa. Caxias do Sul: Educs, 2005.

PANHAN, H. M. S. A tecnologia no espaço clínico e terapêutico fonoaudiológico. Temas sobre Desenvolvimento, v.10, p.55-58, 2001.

PARETTE, H. P.; BROTHERSON, M. J.; HUER, M. B. Giving family a voice in augmentative and alternative communication decision making. Education and Training in Mental Retardation and Developmental Disabilities, v.35, p.177-190, 2000.

PAULA, P. M. K.; NUNES, P. O. R. L. A comunicação alternativa no contexto do ensino naturalístico. In: NUNES, P. O. R. L. (Org). Favorecendo o desenvolvimento da comunicação em crianças e jovens com necessidades educacionais especiais. Rio de Janeiro: DunYa Qualitymark Editora, 2004.

PERES, A.; SANCHES, S.; SEVILHA, A. Relato de caso: a família como importante parceria no trabalho interdisciplinar em CSA. In: CONGRESSO BRASILEIRO DE COMUNICAÇÃO ALTERNATIVA, 2., 2007, Campinas. Anais...,Campinas, 2007, p.15-19.

REILY, L. Escola inclusiva: linguagem e mediação. São Paulo: Papirus, 2006.

SORO-CAMATS, E. Uso de ajudas técnicas para a comunicação, o jogo, a mobilidade e o controle do meio: uma abordagem habilitadora. In: ALMIRALL, B. (Org.). Sistemas de sinais e ajudas técnicas para a comunicação alternativa e a escrita: princípios teóricos e aplicações. São Paulo: Livraria Santos Editora, 2003.

SOUZA, J. S. Infância e linguagem: Bakhtin, Vygotsky e Benjamin. 10. ed. Campinas: Papirus, 2006.

VASCONCELLOS, R. Clínica de linguagem e sujeitos com paralisia cerebral que não oralizam: particularidades na introdução dos sistemas suplementares e alternativos de comunicação. In: DELIBERATO, D.; GONÇALVES, M. J.; MACEDO, E. C. (Org.). Comunicação alternativa: teoria, prática, tecnologias e pesquisa. São Paulo: Memnon Edições Científicas, 2009. p.87-95. 
KRÜGER, S.; BERBERIAN, A. P.; GUARINELLO, A. C.; CARNEVALE, L. B.

VON TETZCHNER, S. et al. Inclusão de crianças em Educação pré-escolar regular utilizando comunicação suplementar e alternativa. Revista Brasileira de Educação Especial, Marília, v.11, n.2, p.151-183, 2005.

Recebido em: 31/08/2010

Reformulado em: 11/04/2011

Aprovado em: 18/05/2011 